\title{
Collaborating For Success: Team Teaching The Engineering Technical Thesis
}

Terrence Keating, College of the North Atlantic- Qatar, Qatar

Mike Long, College of the North Atlantic- Qatar, Qatar

\begin{abstract}
This paper will examine the collaborative teaching process undertaken at College of the North Atlantic-Qatar $(C N A-Q)$ by Engineering and the Communication faculties to improve the overall quality of engineering students' capstone projects known as the Technical Thesis. The Technical Thesis is divided into two separate components: a proposal stage (Tech Thesis 1-investigative) and a technical/presentation stage (Tech Thesis 2 - final written and oral communicative report). It involves a complex blending of experimentation, technical information and data with competent formal technical report writing skills. In an EFL (English as a Foreign Language) environment, this challenge is formidable for students as it involves high technical as well as linguistic competencies.
\end{abstract}

In an effort to gain accreditation from the Canadian Technology Accreditation Board (CTAB), a standing committee of The Canadian Council of Technicians and Technologists (CCTT) which provides national accreditation for over 240 post-secondary engineering technology and applied technology programs in Canada, the School of Engineering realized student results on the Technical Thesis at CNA-Q needed marked improvement. A pilot project, started during the 20082009 academic year, brought engineering faculty from various fields (Chemical Processing, Electrical, Mechanical, Process Automation and Telecommunications) together with writing faculty from the Communications Department to take on the task of improving final Tech Thesis results through co-delivery.

Specifically, this paper will examine:

- $\quad$ the process of developing the collaborative teaching approach at CNA-Q;

- $\quad$ its perceived value by the stakeholders (faculty and students);

- $\quad$ the ongoing challenges associated with its delivery;

- $\quad$ and the overall level of improvement in student performance on the Technical Thesis as a result of the collaboration.

Keywords: Technical Thesis; Capstone Project; Collaborative or Co-Teaching Teams; Team Teaching; EFL; Accreditation; Writing in Engineering

\section{INTRODUCTION}

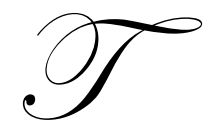

he College of the North Atlantic - Qatar (CNA-Q) is a Middle Eastern satellite of its parent campus in Newfoundland, Canada. In 2002, the College entered into a 10 year comprehensive agreement with the State of Qatar to provide technical education to students in Engineering Technology, Business Studies, Information Technology, Health Sciences, Technical Trades Preparation (TPP) and Security. Over 2000 students are currently enrolled in those programs and another 2500 in our continuing education and contract training division. Instruction at CNA-Q is exclusively in English, although 99\% of our students are non-native speakers of English.

One of the most popular programs at the College is Engineering Technology (414 students - 21\%), which is third behind Business (31\%) and Industrial Trades (22\%). All engineering technology students must complete a 
three year program which culminates in a capstone project known as the Technical Thesis (designated as PR courses in the academic calendar). PR courses are two semesters in length and linked. PR I is a proposal development and planning stage course. PR II is an experimentation, write-up and presentation stage course. The standard PR courses in Engineering are described as follows:

The technical thesis enables the student ... to demonstrate the application of skills and knowledge developed throughout the program. Students taking this course will work with minimal supervision on a project under the guidance of a faculty member. The student can work independently or in teams of two to carry out and in-depth study of a problem, design or technological application, and fully document and present their findings.

Students should commence planning for (PR) courses at the beginning of their final year of studies. Since the project and report are to be prepared through independent study, the assigned hours represent only part of the time that students are expected to allocate to the course. Regular meetings with a faculty supervisor will be scheduled within the assigned hours and it is mandatory that students attend these meetings. This course will be co-delivered to the students by a technical instructor and a communications instructor. (CNAQ, p. 233)

CNA-Q's Engineering Technology program had its first intake of students in September 2002, but it was 2005 before students enrolled in PR courses. And when they did, it became immediately apparent that the course offered a new set of challenges. In addition to those challenges faced by the inherent autonomy of "independent study" and the lack of experience in project management and planning, students were experiencing great difficulties in composing the technical thesis itself. Previous technical theses from the home campus ranged in size, for example, from 25-80 pages, but none of the CNA-Q students had ever crafted a document of such a size. And for them, it was an intimidating prospect. Even for native speaking and writing students at our home campus, PR courses have a reputation as daunting.

As may be expected, results were exceptionally weak. New and old faculty were frustrated by a lack of pedagogical resources and a weakness in student writing/language skills; similarly, students were discouraged by the amount of writing, the volume of expected research reading, the bibliographical scrutiny and the challenges of organizing and composing such a large document. It was, in retrospect, a pedagogical perfect storm.

The grumbling was largely anecdotal and unofficial, however, until the winter of 2007 when, after an accreditation review, the Canadian Technology Accreditation Board (CTAB) noted in its report to the College that the quality of the technical theses produced by students was substandard and needed addressing if accreditation would be forthcoming. This was the event that precipitated a marshalling of institutional resources to address a weakness that may jeopardize the program. What follows is a chronicle of the collaborative efforts to remedy that situation.

At the early stages of PR instruction, stop gap measures were employed. Assessments by engineering instructors would de-emphasize the importance of the theses document and emphasize the science. Faculty made extra office hours available for discussions on PR projects. Engineering students began utilizing their Communications instructors for writing concerns with their technical theses. And right at this time, the College fortuitously opened its Learning Commons that housed its Advanced Writing Centre (AWC). The AWC was particularly busy with both visits from PR students and meetings with faculty on issues ranging from thesis development and literature reviews to bibliographies and sentence structure. While the technical thesis was clearly posing a problem, the serendipitous fallout was that a new interdisciplinary dialogue was taking place among faculty and students on the subject of writing.

Those early meetings and consultations with students and faculty made clear a number of points. They highlighted the lack of uniformity in the course, the broad range of expectations from both faculty and students, the undefined nature of a technical thesis at our institution, the lack of resources for the course (particularly given that it was operating in an EFL environment) and a reinforcement of the importance of writing skills to student success.

In addition to regular mentoring sessions, the AWC developed a series of resources for Engineering students on a variety of topics pertaining to the technical thesis such as handouts on conducting a literature review 
for engineering, the structure and components of a proposal, writing problem statements, constructing Gantt charts and finally, after much discussion with Engineering faculty members, particularly with Paul Singh from Chemical Processing Technology, a proposal template for PR courses. In fact, early efforts at team teaching were experimented with between the Advanced Writing Centre and Singh's PR courses for Chemical Processing Engineering students.

Simultaneously, another initiative to improve student performance on the technical thesis was evolving. All engineering students must complete a senior writing course called Communications 2300 (CM 2300) which effectively is a formal report writing course. With the cooperation of the Dean of Language Studies and Academics, Engineering students were scheduled in CM 2300 classes, when possible, to have those who were also taking the PR courses. CM 2300 classes were then being utilized by faculty and students as a place where portions of their technical thesis could be explored and developed.

Perhaps the clearest formal sign, however, of the College's willingness to overcome the issue with student performance on the technical thesis was the fact that human resources were allocated exclusively for the purpose. In September 2008, Bruce Barbour, a professional engineer and long time faculty member in Mechanical Engineering with the parent campus, was hired for the Qatar project. In addition to duties in Mechanical Engineering, Barbour was hired to address the technical thesis "issue". He had years of experience with PR courses on the Canadian campus, had worked in South America on similar projects for the parent campus and was deeply involved in the accreditation process in Canada as well. This knowledge and experience was instrumental in providing Engineering leadership to the PR capstone program. With Paul Singh and the AWC, the group designed a series of workshops to address weaknesses in the skill sets of PR students. Workshops were designed and delivered on

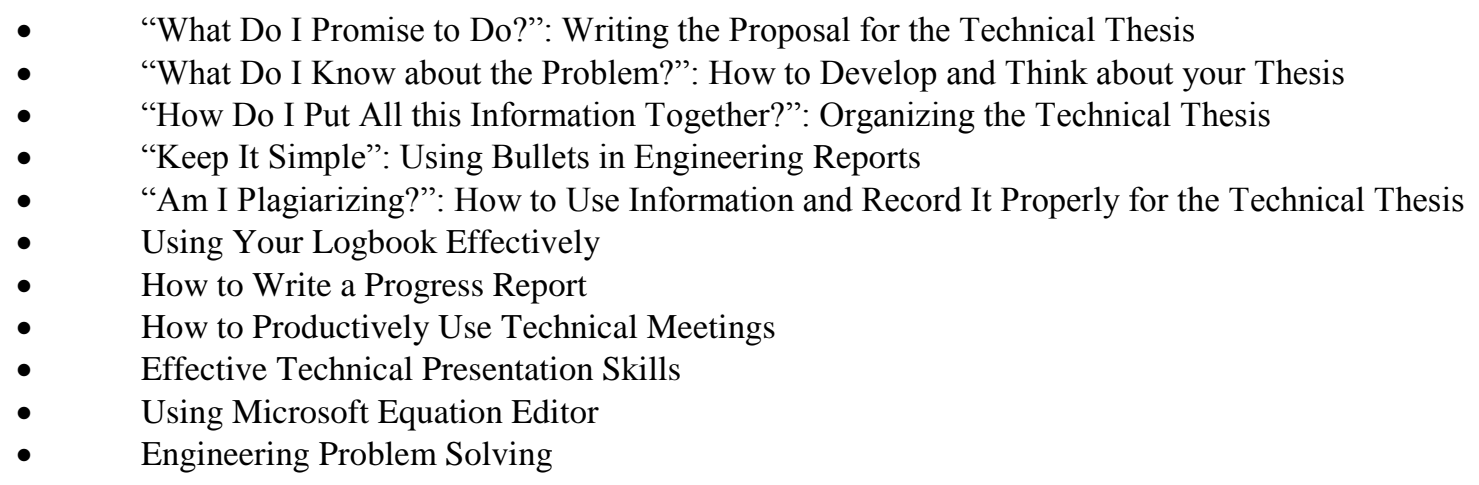

Other changes brought to the process of teaching the technical thesis included a requirement that students keep a documentation portfolio to record literature reviews and textual research. Rubrics and evaluation reports were developed for faculty members to assess the theses. Perhaps most importantly, a finalized (but not mandatory) technical thesis template was developed which helped both students and faculty see what the final product might look like. Also, to incentivize success, a competition was started with prizes awarded for the top thesis in each branch of Engineering.

Given the measureable improvement witnessed in the quality of the projects, the final reports and the presentations on those reports as a result of the interdisciplinary team approach, a broader experiment with coteaching was formalized in September 2009. Dr. Lori Bradshaw provided initial workshops to Engineering and Communications faculty on

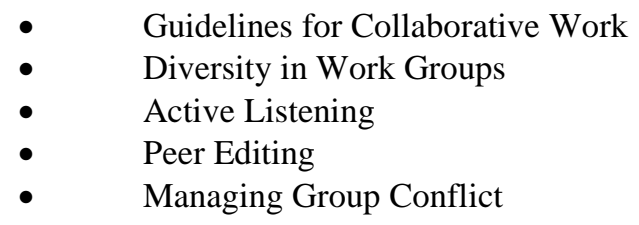


A Communications instructor was paired with an Engineering Instructor for the delivery of the PR course (whether PR I or II). All instructors and students met during a common hour where a lecture was given on a topic of importance to the thesis. Sample topics included subjects such as writing progress reports, evaluating internet sources, APA documentation, writing in the passive voice and giving engineering presentations. It was also an opportunity for students (and faculty on occasion) to ask questions or raise concerns. It was also instrumental in fostering a project and writing community by bringing everyone together for that weekly meeting. Previously, PR courses were regarded as very solitary experiences, so the group dynamic helped to combat that isolationism and imbue the program with an identity and spirit.

All PR courses are allocated 3 (PR I) to 5 (PR II) hours per week. Of those hours, Communications instructors spent approximately 3 hours with both the engineering student and the faculty member while working on the technical component of the project. For the Communications instructor the time was used to work on the written elements of the course, but also to become more familiar with the technical side of the project. Indeed, many CM instructors reported that exposure to and immersion in the engineering side of the projects that came from these "break-out sessions" was instrumental in becoming more closely connected to the project.

While resources developed for the PR courses began long before September 2009, it was not until Ian Brockie, CM Technical Thesis Mentor, took control of those resources that they were streamlined, unified, and branded. Even at this late stage, for example, rubrics remained vague and underdeveloped. Brockie examined the minutiae of the learning process inherent in PR courses and created a series of rubrics to assess key learning outcomes. This work was continued by the current Mentor, John Little, who also lead team teachers in the process of eliminating the bureaucracy of formalized evaluation and moving the initiative towards a more process oriented experience.

While considerable resources have been summoned for the co-teaching initiative, no formal evaluation of the effort had taken place until January 2011. That evaluation, and consequently this research, ultimately came about from a request by Jason Rolls, Dean of Language Studies and Academics, to examine the effectiveness of the entire program in terms of man hours dedicated to the initiative and measurable success of student performance on the technical thesis. To that end, in addition to data analysis of historical student performance, a series of surveys and interviews were designed and conducted to gauge the efficacy of co-teaching between Engineering and Communications faculty.

\section{PERCEPTION SURVEY FINDINGS}

As part of the research process, two perception surveys were designed. The first entitled Student Perceptions of Co-Teaching Engineering PR Courses collected information from 19 of 40 students currently enrolled in PR courses at CNA-Q. The survey was open for a 40 day period from March 01, 2011 to April 10, 2011. The second entitled Faculty Perceptions of Co-Teaching Engineering PR Courses collected information from 11 of the current 15 instructors co-teaching the PR courses and remained open for a 25 day period from March 16, 2011 to April 09, 2011. Both surveys were constructed using an online survey design template from Vovici Corporation (2011) ().

The student survey contained 15 five-point Likert scale type statements under three headings:

- "Skills Improvement",

- $\quad$ "Instructor Assessment" and

- "Student Assessment of Co-Teaching Experience and Initiative".

Students could either select "Strongly Agree", “Agree", "Neutral”, "Disagree" or "Strongly Disagree" after reading the statement. Student responses to the questions revealed the experience of, and exposure to, the team teaching approach was quite positive. Samples of those statements and tabulated student responses for those "strongly agreeing" and "agreeing" to the statements are listed in Table 1. 
Table 1: Sample Student Responses On Perception Survey, April 2011

\begin{tabular}{|c|c|c|c|}
\hline \multicolumn{4}{|c|}{ Student Perception Survey - Sample Likert scale Results } \\
\hline Statement & \% Strongly Agree & $\%$ Agree & Total \% \\
\hline "Both instructors treat us fairly and courteously within the classroom." & 66.7 & 33.3 & 100 \\
\hline "I was given the skills to present my Technical Thesis verbally and visually." & 55.6 & 38.9 & 94.5 \\
\hline $\begin{array}{l}\text { "Working with two instructors (Communications and Engineering) in my PR course was } \\
\text { extremely helpful." }\end{array}$ & 72.2 & 22.2 & 94.4 \\
\hline "Courses taught by two instructors are better than courses taught by one instructor." & 55.6 & 33.3 & 88.9 \\
\hline $\begin{array}{l}\text { "PR courses should continue to be delivered with two instructors for future Technical } \\
\text { Thesis students." }\end{array}$ & 61.1 & 27.8 & 88.9 \\
\hline
\end{tabular}

Students felt that the collaboration between the two instructors provided a positive learning environment and gave them opportunity to further improve both their technical expertise in the various engineering areas (listed below) and their report writing and presentation skills. Engineering students were enrolled in the areas of Chemical Processing Technology (PR 3721/PR 3211), Electrical Engineering Technology (PR2511/PR 3221), Process Automation Engineering Technology (New program), Mechanical Engineering Technology (PR 3611/PR 3241), and Telecommunications (PR 2601/PR 3251). An Evaluation Rubric is used by evaluating instructors for both the oral and written components. With $94.5 \%$ of students "strongly agreeing" or "agreeing" with the statement "I was given the skills to present my Technical Thesis verbally and visually" we clearly see that students felt confident with their chances of success.

The team teaching of PR courses received very positive feedback from the faculty involved as well. They responded to 25 Likert scale type questions under five different headings:

- "Writing and Technical Resources for PR"

- "Perceptions"

- "Co-Teaching Dynamic"

- "Support for Co-Teaching" and

- "Impact of Co-teaching".

They too could either select "Strongly Agree", "Agree", "Neutral", "Disagree" or "Strongly Disagree" after reading the statement. Samples of those statements and tabulated faculty responses for those "strongly agreeing" and "agreeing" to the statements are listed in Table 2.

Table 2: Sample Faculty Responses On Perception Survey, April 2011

\begin{tabular}{|c|c|c|c|}
\hline \multicolumn{4}{|c|}{ Faculty Perception Survey -Sample Likert scale Results } \\
\hline Statement & \% Strongly Agree & \% Agree & Total \% \\
\hline $\begin{array}{l}\text { "I feel teaching a PR course in this fashion has been a positive experience for me } \\
\text { educationally." }\end{array}$ & 72.7 & 27.3 & 100 \\
\hline $\begin{array}{l}\text { "Student results on the Technical Thesis have improved because of the co-teaching } \\
\text { approach in the PR courses." }\end{array}$ & 81.8 & 18.2 & 100 \\
\hline $\begin{array}{l}\text { "Our departments should continue the co-teaching of Engineering Technical Thesis } \\
\text { courses." }\end{array}$ & 63.6 & 27.35 & 90.95 \\
\hline $\begin{array}{l}\text { "The writing and technical resources produced for PR courses are consistently } \\
\text { utilized." }\end{array}$ & 18.2 & 63.6 & 81.8 \\
\hline $\begin{array}{l}\text { "Course planning is fairly shared between the Engineering and Communications } \\
\text { instructor in my PR course(s)." }\end{array}$ & 9.1 & 72.7 & 81.8 \\
\hline
\end{tabular}

Further to this, there was also a $100 \%$ agreement among instructors that "the team teaching approach had improved the written quality and the visual and oral presentation of the Technical Thesis" (Faculty Perception Question). The interdisciplinary approach to team teaching the courses combined the technical expertise of the Engineering faculty with the report writing skills of the Communications faculty in a successful way for both students and faculty. Jordan (1997) in support of these ideas stated:

Essential elements needed for successful team-teaching: willingness to collaborate on the part of both sets of staff; clear demarcation as to where their respective responsibilities lie; awareness of each other's conceptual apparatus and teaching approach; and the joint effort being viewed by the student as a complementary teaching situation. (p.121) 
It was this complementary teaching situation that received support and praise from both students and faculty. Faculty highlighted the enjoyment of working with another instructor from a different department and most importantly stressed the continued improvement of the "quality" of Technical Theses being produced by their students since the introduction and continued use of the team teaching approach in PR coursework.

\section{ADDITIONAL EMPIRICAL RESULTS}

In addition to the Perception Surveys, an examination of PR course results was conducted for three semesters in a "pre" team teaching period (Winter 2008, Fall 2008 and Winter 2009) and a "post" team teaching period (Fall 2009, Winter 2010 and Fall 2010). The results were tabulated from official Grade Rosters released from the College's Registrar's Office. As noted in Table 3 below, most PR courses also received numbering changes though remained course equivalencies. The results revealed a marked, but slight, improvement overall which was attributed to several variables when interviewed instructors were informally questioned. They stated "high instructor turnover in the early days of the College", "the work ethics of different student cohorts" and "the increased instructor expectations of team teachers in the PR courses" as the most notable. The instructors added that the noticeable improvement in the "quality" of the final products was evident, as has already been highlighted in the responses on the Faculty Perception Survey above.

Table 3: Pre And Post Team Teaching Final PR Grade Average Results

\begin{tabular}{|l|c|c|c|c|c|c|}
\hline Course/Equivalent & Winter 08 -Pre & Fall 08- Pre & Winter 09- Pre & Fall 09- Post & Winter 10 - Post & Fall 10- Post \\
\hline PR 2601/PR 3251 & $56.30 \%$ & $55.50 \%$ & $53.80 \%$ & $73.30 \%$ & $73.80 \%$ & $79.40 \%$ \\
\hline PR 3611/PR 3241 & $40 \%$ & $63.10 \%$ & $58.30 \%$ & $43.30 \%$ & $66.50 \%$ & $70 \%$ \\
\hline PR 3721/PR 3211 & n a & $70 \%$ & $70 \%$ & $62.20 \%$ & $61.20 \%$ & $80 \%$ \\
\hline PR 2511/PR 3221 & $65 \%$ & $75 \%$ & $71.70 \%$ & $77.50 \%$ & $75 \%$ & $90 \%$ \\
\hline
\end{tabular}

The results from Table 3 are given in graphical format as well in Figure 1 to illustrate the upward movement in the actual course results in the various PR courses from the differing Engineering areas.

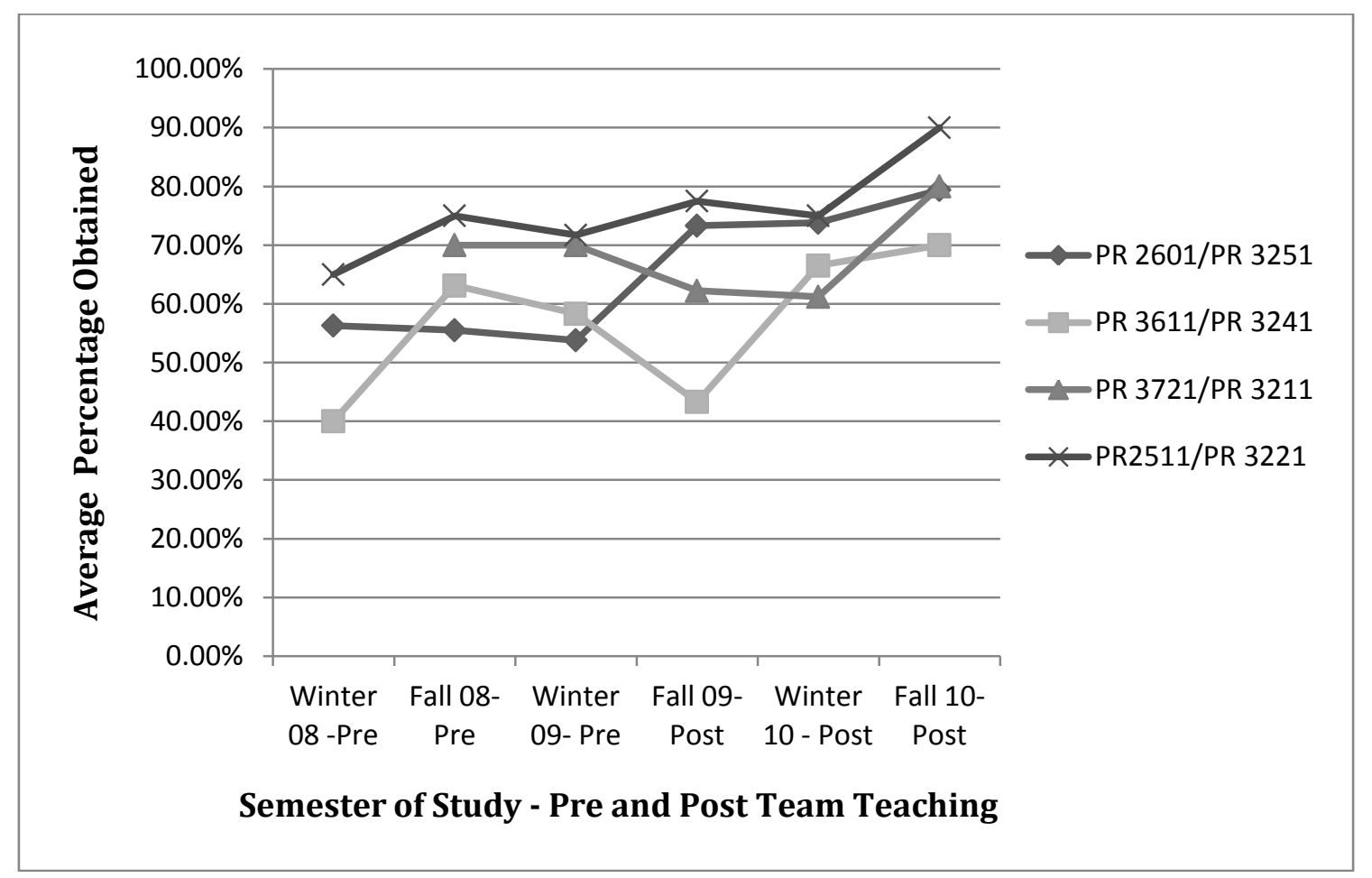

Figure 1: Grade Roster Results for PR Courses Over Selected Time Period 
An increase in student results can be easily seen from the measured starting point (Winter 2008 in all cases but one) until the end point of measure (Fall 2010). Although this is a relatively short time frame, the team teaching approach appears to be a major factor in the measured increase in results.

\section{INTERVIEW FINDINGS}

Everyone has a different perspective even on shared experiences. Formalized structured interviews, lasting on average forty-five minutes, were conducted with eight instructors who had experience team teaching PR courses in Engineering. Four instructors were from the School of Engineering and four taught Communications within the School of Academics at CNA-Q. A summation of their differing perspectives and their ideas on and recommendations for improvement to the team teaching process follows.

\section{Experience}

All interviewees had extensive experience with the team teaching approach at CNA-Q having been involved since its inception. The actual full team teaching of PR courses commenced in the Fall 2009 semester, but early consultation on modifications to course objectives, mentoring of students in writing and on technical topics, and the provision of the CM Technical Thesis Facilitator began in the Fall of 2008. One Engineering instructor was well versed in team teaching having carried it out for several years in the United Arab Emirates and in eastern Canada. The comfort level of all interviewees with the collaborative team teaching approach was evidently high.

\section{Advantages and Disadvantages of Team Teaching}

Students learn through a variety of learning styles and each may be engaged by a different method of delivery. Different teaching styles may therefore make the learning experience more inclusive (Neumann, July 2006, p.4). One of the repeated listed advantages of team teaching was that the differing teaching styles of the two instructors was of great benefit to the students enrolled in the courses and that a "culture of collaboration" developed because of the presence of these differing teaching styles and methodologies. Felder and Silverman's 1988 paper entitled Learning and Teaching Styles in Engineering Education has become a cornerstone for examining models of learning and teaching styles and the effective matching of these in Engineering Education classrooms. With the addition of another instructor from a writing background, it would seem that the learning and teaching style "mismatches" Felder and Silverman researched that exist between engineering instructors and students would be lessened and that students would be the winners in the co-teaching classroom as a result. As noted, this was an advantage alluded to by all interviewees. It also fits well with the College's newly released five year Strategic Plan which has "Learners First" listed as its key focus area (the others being "Educational Innovation", "Exceptional Collaboration", "CNA-Q Pride" and "Leaders in Communication").

This "learners first" focus was repeated by all interviewees when they stated that the entire team teaching approach was initiated to assist students in making improvements in their Technical Theses, with the School of Engineering obtaining accreditation as a secondary benefit from the process. Interviewees felt students have become accustomed to having two equally important instructors as part of their PR courses and had become "quite comfortable" (as quoted from an actual interviewee) with teaching this way. Students realized very early in their course work the "advantages" of having both technical experts in core content areas, as well as research, writing and presentation faculty available to them.

However, many interviewees stated that there was a high level of "discomfort and disconnect" when the team teaching approach first started. The engineers felt that language issues and paper presentation were not their areas of strength and the Communications faculty felt overwhelmed by the technical concepts and jargon. The continued exposure to the dual roles has help break down many of these "barriers to cooperation" and instructors now realize their important individual parts in the process of making a team teacher feel comfortable. They felt classroom dynamics have "improved greatly since those early days" and that respect for their individual roles has made the entire experience "educationally enjoyable and beneficial". Instructors also "learned from each other" noting that obvious differences in teaching styles existed, but that the educational opportunity to participate in team teaching made the entire "growing process" worthwhile. Having noted this, several instructors stated that 
"personality differences" are bound to exist and that sometimes an environment of uncooperativeness occurred initially. Most instructors, with experience in the team teaching process, felt that their professionalism and desire to assist students succeed often quickly eliminated this.

\section{Recommendations And Directions}

One of the recurrent themes surfacing from the interviewees was the concept of "flexibility". Instructors felt that the extensive resources developed for the PR courses needed to be utilized in a flexible manner. There is now an abundance of resource materials, so not all can be used. Instructors should be able to "pick and choose" resources as they see fit - that is, in a manner which best allows the course objectives (which vary by engineering area obviously) to be covered most effectively. These resources are continually being modified and enhanced by the team teachers as the experience with team teaching the courses matures.

When the team teaching approach was first initiated all students in the differing PR courses (PR 1 students and PR 2 students separately of course) met as a large group for writing and presentation instruction. After the presentation of materials they would form "break-out groups" and go off and work with their specifically assigned Engineering and Communications instructors on their chosen Technical Thesis projects. Some interviewees felt this made some instructors overly reliant on the efforts of other instructors because this part of the instruction was "out of their element". Many current instructors see the value of quickly forming separate small groups within the differing engineering areas and working closely with both team teachers as being more beneficial for students and instructors. This method is currently employed by team teachers teaching the various PR courses and came as the recommended way of doing things.

Most engineering instructors also felt their roles in the teaching process were more "informal and handson" than the Communications instructors, who felt they presented information in a more structured and traditional fashion. These differences were seen as a good thing overall, though being aware of the differences in responsibility needed to be established early in the team teaching process. The small group method noted above created a working environment where students quickly saw the importance of blending the more informal structure of learning the technical content with the more structured and formalized process of researching and presenting that technical information in their final Technical Thesis. Again, team teachers felt that this recognition of the different roles within the classroom and in the learning process was beneficial for all involved.

Another interview point that continually surfaced was the need to recognize that instructors are working with students in an EFL environment and that this presents its own set of difficulties for instructors who may not be EFL trained or experienced. Teaching English for Specific Purposes (ESP) to engineering students is paramount to their success in the field, especially when working with other English speakers or companies using English. Some training in EFL was noted as being crucial for instructors by several interviewees. The fact that most instructors stated they were also teaching and delivering instruction in a very different cultural environment than their own was noted. Dudley-Evans and St-John (1998) stated that in all ESP work we now recognize that we have to be sensitive to cultural differences, both in the academic and professional worlds (p.18). The combination of teaching in an EFL environment and using ESP with students from a variety of different cultures was challenging. The engineering instructors, for example, complimented and stressed the abilities of many of their team teaching partners from Communications because most possessed experience with EFL and the use of ESP in engineering. They felt this alleviated stress from their teaching loads and that it was another positive reason to continue with the team teaching process in this manner.

Several recent developments in the on-going process to improve the team teaching have occurred. Instructors met and decided on revisions of all evaluation documents, trimming the total number of evaluation forms from 12 to only 6 , which will be simpler for everyone. They now have only one evaluation form for each type of assignment in PR (they used to have separate ones for drafts and final copies, but now will utilize the same one, which has been revised to reflect what they really want to evaluate).

This will likely be a process of continuous redevelopment as they get more of a handle on what the programs demand; as new staff come in; and as new leadership emerges because numerous faculty and leadership 
positions are currently being refilled in both the School of Engineering and the School of Academics department of Communications. One very positive element was that "many voices" took part in changing the forms and there was a lot of agreement and positive feedback in the workroom, which marks a strong change from the initial meetings which were held at the start of the PR team teaching initiative, when there were only two people running it and when little feedback was given. For example, the fact alone that 6 PR instructors took time out of the busy first week of Intersession (May 2011) to improve upon grading sheets they will not see or employ until September 2011, speaks to their desire to "getting this thing right".

\section{CONCLUSION}

The process is "not perfect" but the team teachers interviewed felt that with minor, but continued, alterations to the materials and the methodologies for the delivery of those materials, the approach will further improved the quality of capstone Technical Theses. The courses are demanding for students and instructors in terms of the amount of material to be covered, the pace at which that material is covered, and the expectations for high quality. Admittedly, our team teaching initiative is rather product oriented towards a successful final document - the technical thesis - perhaps at the expense of the process (es) needed. But changes are taking place that indicate an evolution away from product towards process oriented learning and writing. Students and instructors now comment on how the initial templates are constraining in scope or do not accommodate particular technical projects (such as projects involving complex and time consuming programming.) Additionally, students deviate from suggested organizational and formatting norms by including, for example, elaborate video components to their theses. Furthermore, in the past, topics for technical theses were often provided to students by faculty members, but increasingly we are seeing student projects of their own devising on particularly local subjects (i.e. solar generators for desert camping, green air-conditioning and real ecological concerns as reflected in the Qatar 2030 National Vision document.) The courses will continue to pose challenges, but with a supportive and collaborative approach, success for all involved is much more likely.

\section{AUTHOR INFORMATION}

Terrence J. Keating B.A, M.Ed., Born and raised in Newfoundland, Canada, Terrence (Terry) received undergraduate degrees (B.A, B.Ed- Secondary) from Memorial University of Newfoundland in 1985. His teaching career started in 1985 and continues today. He attained a Masters Degree from the University of New Brunswick in 2007 in Educational Foundations with work in the areas of Administration, Curriculum Development and Supervision of Instruction. He is currently employed as the Chair of Academics at the College of the North Atlantic - Qatar in Doha, Qatar. Family, friends, sports and extensive world travel with his wife, Lori, complement his working life. E-mail: terrence.keating@cna-qatar.edu.qa. Corresponding author.

Dr. Michael Long Ph.D., Mike is currently the Chair of Applied Research and Innovation at the College of the North Atlantic-Qatar. He has been working in post-secondary education for 19 years, the last of 8 of which has been in Qatar where he worked as Technical Thesis Mentor, established and coordinated the College's Writing Centre. He holds undergraduate degrees in literature and Education, and graduate degrees from the University of Toronto and Oxford University. E-mail: mike.long@cna-qatar.edu.qa.

\section{REFERENCES}

1. College of the North Atlantic- Qatar (2010). Academic Calendar 2010-2011. CNA-Q, Doha, Qatar.

2. Dudley-Evans, T. and Jo St-John, M. (1998). Developments in ESP: A multi-disciplinary approach. Cambridge University Press, Cambridge, UK.

3. Felder, R.M., and L.K. Silverman (1988). "Learning and Teaching Styles in Engineering Education." Engineering Education 78: 674-681.

4. Jordan, R.R. (1997) English for Academic Purposes: A guide and resource book for teachers. Cambridge University Press. Cambridge, U.K.

5. Neumann, M (Chair) et al (2006). Team Teaching - A Survey. University of Toronto Learning Community, July 2006. Toronto, Canada. 
NOTES 